\title{
Cardiac surgery in Wessex: review of 1000 consecutive open-heart procedures
}

\author{
J K ROSS, J L MONRO, J M MANNERS, J C EDWARDS, B LEWIS, I HYDE, N CONWAY, \\ A M JOHNSON
}

British Medical fournal, 1976, 2, 1485-1489

The regional structure of the National Health Service enables specialist regional units to monitor both the amount and the quality of the work they do in relation to the population they serve and the facilities at their disposal. This applies particularly to the specialist unit holding a monopoly position in its region such as the cardiac surgical service in Wessex. This paper reports a review of 1000 consecutive open-heart procedures carried out in the Wessex regional unit at Southampton from September 1972 to April 1976.

\section{Wessex Region and facilities}

The Wessex Region covers central southern England and includes the counties of Hampshire, Dorset, and Wiltshire and the Isle of Wight. The population is 2.7 million and the annual birth rate is 12.7 births per 1000 population (1974).

The cardiothoracic unit has 20 beds allocated for cardiac surgical patients, including a paediatric unit separate from the adult beds; four intensive care beds; and two operating theatres providing 10 cardiac operating sessions a week. The great majority of the cardiac work is done in one operating theatre during eight of the available

Wessex Cardiac and Thoracic Centre, Southampton Western Hospital, Southampton.

J K ROSS, MS, FRCS, consultant cardiac surgeon

J L MONRO, FRCS, consultant cardiac surgeon

J M MANNERS, FFARCS, consultant anaesthetist

J C EDWARDS, FFARCS, consultant anaesthetist

B LEWIS, AIST, chief perfusion technician

I HYDE, FRCPED, FRCR, consultant radiologist

N CONWAY, FRCP, consultant cardiologist

A M JOHNSON, MD, FRCP, consultant cardiologist sessions, two of the sessions being used flexibly as the work load and staffing dictates.

Two consultant cardiac surgeons are supported by one senior registrar, one registrar, and one senior house officer. The junior staff rotate with their opposite numbers in the thoracic surgical service. Two consultant cardiologists, supported by one lecturer, one registrar, and two senior house officers, together with (for the period of this report) one consultant radiologist, are responsible for investigating 13-18 cases each week by cardiac catheterisation and angiocardiography. About $70^{\circ}$ of those investigated are subsequently referred for surgery, and all investigations are carried out in a single laboratory, which is generally recognised to be inadequate.

After they have been accepted for surgery patients are given a clear indication of when their operation is likely to be. So although the average waiting time for elective surgery is about six weeks, the element of uncertainty that goes with the conventional waiting list is removed. Emergency cases are dealt with as they arise.

Two consultant anaesthetists and supporting junior staff (who are rotating through multiple training posts) are responsible for the anaesthetic care and postoperative respiratory care of the patients. The surgical staff carry overall responsibility for the immediate postoperative management in the intensive care unit. Responsibility for the conduct of perfusion, and the care and maintenance of the heartlung and monitoring machinery used in the operating theatre, is taken by one senior and two other technicians. All three are fully trained and experienced in perfusion work and are an integral part of the surgical team. A 24-hour laboratory service is provided for blood gas and electrolyte estimations and any other investigations that may be required. The Wessex regional blood transfusions service and the haematology department at the Southampton General Hospital supply whole blood and other blood elements as well as providing a preperfusion blood screen for coagulation and other defects. An aortic homograft valve bank run by a whole-time technician provides a steady supply of this type of biological valve for clinical use.

\section{Patients and methods}

The patients undergoing operation from September 1972 to April 1976 varied in age from 1 day to 74 years, and about $10 \%$ of the 1000 
operations were performed as emergencies. Of the patients undergoing valve replacement $20 \%$ had had previous valve surgery and $10 \%$ had a history of bacterial endocarditis. Most of those coming to surgery were investigated by cardiac catheterisation and angiocardiography, but this was not always performed if the diagnosis was clear on clinical and non-invasive investigation, or in cases of extreme emergency.

In most cases a conventional anaesthetic technique was used consisting of thiopentone induction followed by nitrous oxide supplemented with intravenous phenoperidine and muscle relaxation with pancuronium.

Conventional normothermic perfusion was used in adults, using bubble oxygenators with a Ringer-lactate solution prime, and a flow rate of $2.41 / \mathrm{m}^{2}$. In children perfusion with moderate $\left(28^{\circ} \mathrm{C}\right)$ hypothermia was often preferred and in infants and children (weighing $10 \mathrm{~kg}$ or less) requiring intricate correction of complex congenital lesions, profound hypothermia with circulatory arrest and rewarming on bypass ${ }^{1}$ was our standard practice. The average perfusion time for single prosthetic valve replacement was 50 and 65 minutes for mitral and aortic valves respectively, 120 minutes for homograft aortic valve replacement, and 95 minutes for replacement of both aortic and mitral valves. Throughout the series an average of about four units of blood per person was used, for both adults and children.

Postoperatively all patients were returned to the intensive care unit and their progress was followed by routine monitoring of right and left atrial pressures, arterial pressure, urine output, blood drainage, and the electrocardiogram. Serial blood gas and serum electrolyte estimations and portable chest radiography also formed an essential part of the postoperative management.

The policy regarding postoperative ventilation was adjusted to the individual patient, but in practice most adults were ventilated during the first night after operation and the endotracheal tube was removed early the next morning. Most children and infants were extubated within two or three hours of return to the intensive care unit, where the average stay for adults was 48 hours and for children 24 hours. The average stay in hospital after surgery was 9 to 12 days.

\section{Results}

Table I shows the breakdown of the 1000 operations in this series; 676 operations were for acquired and 324 for congenital heart disease.

TABLE I-Types of operations performed

\begin{tabular}{c|c|c}
\hline & $\begin{array}{c}\text { No of patients } \\
\text { (and No of deaths) }\end{array}$ & $\begin{array}{c}\text { Hospital mortality } \\
\left({ }^{\prime},{ }_{0}\right)\end{array}$ \\
\hline Acquired disease: & $557(27)$ & 4.8 \\
Valve replacement procedures & $20(1)$ & $1 \cdot 7$ \\
Conservative valve procedures & $59(1)$ \\
$\begin{array}{c}\text { Isolated coronary artery bypass grafts } \\
\text { Miscellaneous }\end{array}$ & $30(13)$ & 32.5 \\
Congenital disease & $324(48)$ & 14.8 \\
\hline Total & $1000(89)$ & 8.9 \\
\hline
\end{tabular}

\section{ACQUIRED HEART DISEASE}

The largest single group was 557 valve replacements (table II). There were 208 aortic valve replacements with nine deaths in hospital. Seventy-two of these patients had an aortic homograft valve inserted, and one died in hospital. There were 205 operations for mitral valve replacement with 11 deaths and 139 multiple valve replacements with seven deaths. The hospital mortality for the whole group was $4.8 \%$.

Sixty-five of those undergoing valve replacement had simultaneous conservative procedures on other valves or additional procedures performed such as replacement of the ascending aorta, coronary vein grafting, or resection of a left ventricular aneurysm (table III). These are included in the 557 operations detailed in table II and not surprisingly contributed significantly to the overall mortality for the whole group. There were 59 isolated coronary artery bypass graft procedures with one death. Table IV lists all operations including coronary artery bypass grafting.

The 40 miscellaneous operations (table $\mathrm{V}$ ) included the removal of four atrial myxomas presenting in the space of five months. Three were in the left and one in the right atrium. ${ }^{2}$ The four hospital deaths after resection of descending thoracic aortic aneurysms were in patients whose aneurysms had ruptured. In addition to the 21 patients listed in table $\mathrm{V}$ who had resection of a left ventricular aneurysm, eight more
TABLE II-Details of operations for valve replacement

\begin{tabular}{|c|c|c|c|}
\hline Valves replaced & $\begin{array}{l}\text { No of patients } \\
\text { (and No of } \\
\text { deaths) }\end{array}$ & $\begin{array}{c}\text { Hospital } \\
\text { mortality } \\
\left({ }^{\prime \prime .1 .) ~}\right.\end{array}$ & Total \\
\hline $\begin{array}{l}\text { Aortic } \\
\text { (Homografts } 75(1) \\
\text { Mitral } \\
\text { Tricuspid } \\
\text { Aortic and mitral } \\
\text { Aortic and tricuspid } \\
\text { Mitral and tricuspid } \\
\text { Aortic, mitral, and tricuspid }\end{array}$ & $\begin{array}{l}208(9) \\
72(1) \\
205(11) \\
5 \\
103(5) \\
1 \\
11 \\
24(2)\end{array}$ & $\begin{array}{l}4 \cdot 3 \\
1 \cdot 4 \\
5 \cdot 4 \\
4 \cdot 9\end{array}$ & $\left\{\begin{array}{c}\text { Single } \\
\text { valve } \\
\text { replacements: } \\
418(20) ; 4 \cdot 8 \% \\
\text { Multiple } \\
\text { valve } \\
\text { replacements: } \\
139(7) ; 5 \cdot 0^{\prime \prime}\end{array}\right.$ \\
\hline & 557 (27) & $4 \cdot 8$ & \\
\hline
\end{tabular}

TABLE III-Additional procedures performed in patients undergoing valve replacement

\begin{tabular}{|c|c|c|}
\hline & $\begin{array}{c}\text { No of } \\
\text { patients }\end{array}$ & $\begin{array}{l}\text { No of deaths } \\
\text { in hospital }\end{array}$ \\
\hline \multicolumn{3}{|c|}{ Patients undergoing aortic valve replacement } \\
\hline $\begin{array}{l}\text { Ascending aortic replacement } \\
\text { Coronary vein graft } \\
\text { Mitral valve repair }\end{array}$ & $\begin{array}{r}17 \\
7 \\
5\end{array}$ & $\begin{array}{l}1 \\
1\end{array}$ \\
\hline \multicolumn{3}{|c|}{ Patients undergoing multiple valve replacement } \\
\hline $\begin{array}{l}\text { Ascending aortic replacement } \\
\text { Descending aortic replacement } \\
\text { Coronary vein graft } \\
\text { Tricuspid annuloplasty } \\
\text { Resection of left ventricular aneurysm } \\
\text { Resection of left ventricular aneurysm } \\
\text { and coronary vein graft }\end{array}$ & $\begin{array}{r}2 \\
1 \\
5 \\
11 \\
5 \\
3\end{array}$ & 2 \\
\hline \multicolumn{3}{|c|}{ Patients undergoing multiple valve replacement } \\
\hline $\begin{array}{l}\text { AVR, MVR, and tricuspid annuloplasty } \\
\text { AVR, MVR, and coronary vein graft } \\
\text { AVR, MVR, TVR, and coronary vein grafts }\end{array}$ & $\begin{array}{l}7 \\
1 \\
1\end{array}$ & 1 \\
\hline Total & 65 & 7 \\
\hline
\end{tabular}

$\mathrm{AVR}=$ Aortic valve replacement. $\quad \mathrm{MVR}=$ Mitral valve replacement. $\mathrm{TVR}=$ AVR $=$ Aortic valve replacem
Tricuspid valve replacement.

TABLE IV-All operations for aortacoronary vein grafting. Those operation already included in table III are shown in italics

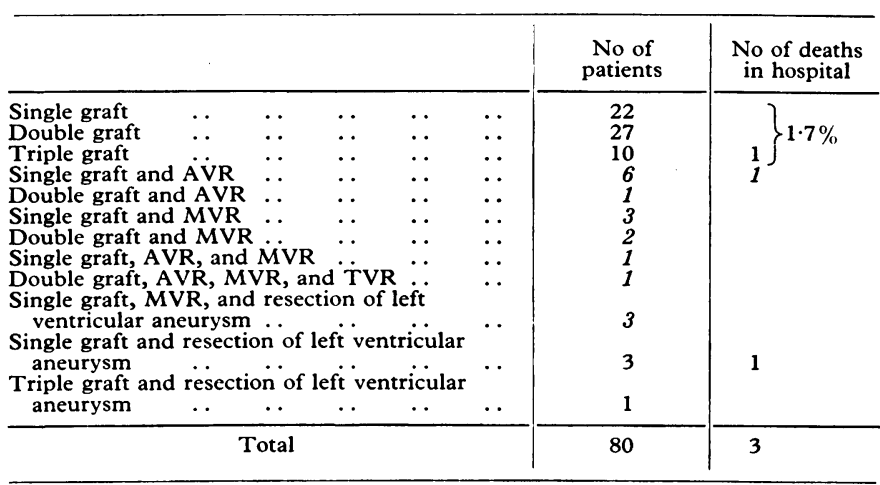

AVR $=$ Aortic valve replacement. $\quad M V R=$ Mitral valve replacement. $T V R=$ Tricuspid valve replacement.

TABLE v-Miscellaneous group

\begin{tabular}{|c|c|c|}
\hline & $\begin{array}{c}\text { No of } \\
\text { patients }\end{array}$ & $\begin{array}{l}\text { No of death } \\
\text { in hospital }\end{array}$ \\
\hline 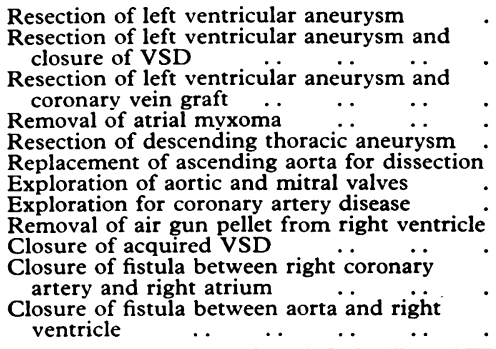 & $\begin{array}{r}13 \\
4 \\
4 \\
4 \\
6 \\
3 \\
1 \\
1 \\
1 \\
1 \\
1 \\
1\end{array}$ & $\begin{array}{l}2 \\
2 \\
1 \\
1 \\
4 \\
1 \\
1 \\
\\
1\end{array}$ \\
\hline Total & 40 & 13 \\
\hline
\end{tabular}

$\mathrm{VSD}=$ Ventricular septal defect 
who had concomitant mitral valve replacements are listed in table III. There were therefore 31 patients who had resection of a left ventricular aneurysm with five deaths (hospital mortality of $16^{\circ}{ }_{0}$ ). The first 20 of these patients have previously been reported. ${ }^{3}$

There were nine deaths among the 93 patients aged over 65 years (hospital mortality $9 \cdot 7^{\circ}$, ). Two of these deaths were among the 11 patients aged over 70 years.

\section{CONGENITAL HEART DISEASE}

Table VI lists the 324 patients with congenital heart disease who underwent open heart surgery. There were 258 patients with the four most common diagnoses of atrial septal defect, ventricular septal defect, Fallot's tetralogy, and pulmonary stenosis. The operative mortality was $6.6^{\circ} \ldots$. The remaining 66 patients with less common and more complex defects suffered an operative mortality of $47^{\circ} \mathrm{o}$. . (During this same period 36 patients underwent closure of a persistent ductus arteriosus, 25 had their coarctations resected, and 20 infants underwent pulmonary artery banding or creation of a shunt). Patients with infundibular stenosis and a ventricular septal defect with left to right shunting were included in the ventricular septal defect group for which the hospital mortality was $5^{\circ}{ }_{1}$. The 19 operations grouped as miscellaneous are shown in table VII.

TABLE VI-Operations for congenital heart disease

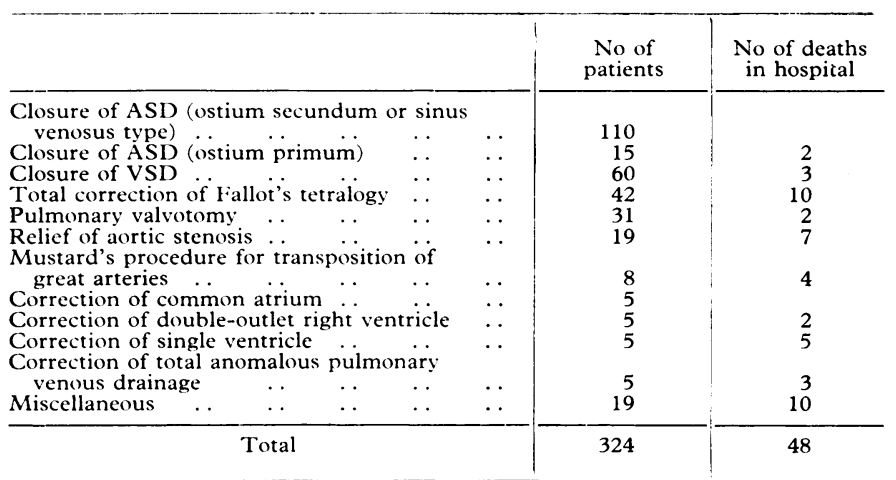

ASI $=$ Atrial septal defect. $\quad$ VSD $=$ Ventricular septal defect.

TABLE VII-Miscellaneous congenital group

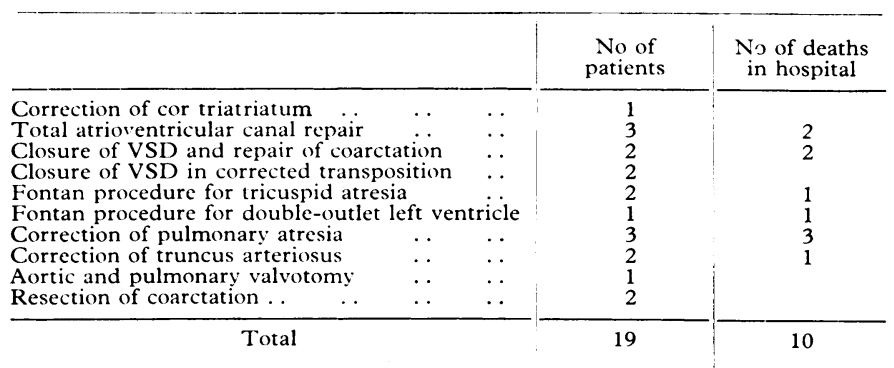

VSD = Ventricular septal defect.

Table VIII shows the distribution of the 56 patients under two years of age, $55^{\circ}$ " of whom died. The mortality for patients aged under 1 year was $69^{\circ}{ }^{\circ}$, .

The two patients with simple transposition of the great arteries who died were 1 and 2 days old, and survived after operation for seven and three days respectively. Both had failed to improve after balloon septostomy, and their deaths were due to septicaemia at seven days in one and respiratory mismanagement at three days in the other.

All six patients who died after aortic valvotomy were shown at necropsy to have endomyocardial fibroelastosis and, although this was suspected preoperatively, relief of the valvar stenosis was considered justifiable under the circumstances. In all, 16 patients in the group with congenital heart disease were considered at necropsy to have been inoperable.
TABLE VIII-Details of conditions and mortality in children aged under 2 years. Numbers of deaths in hospital are given in parentheses

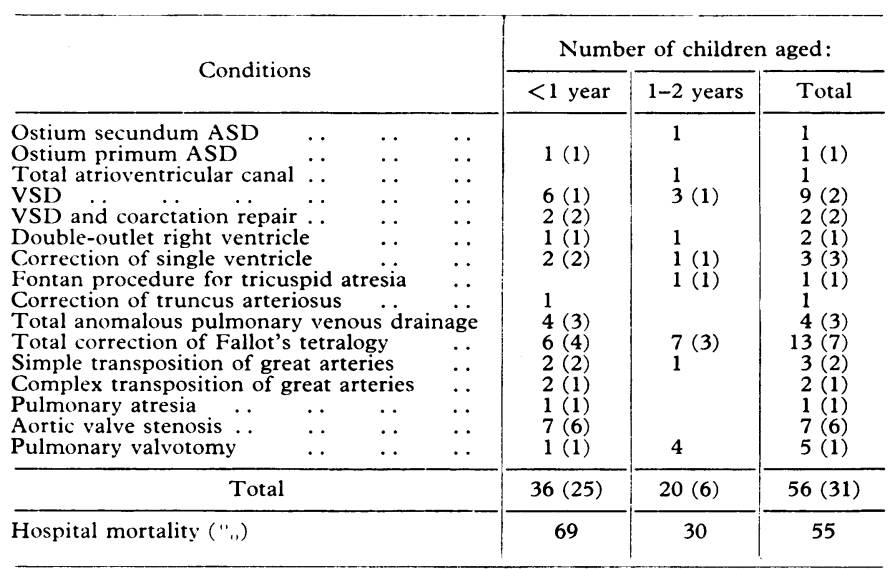

ASD $=$ Atrial septal defect. $\quad$ VSD $=$ Ventricular septal defect. $\quad$ TGA $=$ Transposition of great arteries.

Many of the patients operated on for congenital heart disease were desperately ill. It is gratifying that it was possible to totally correct such challenging lesions in infancy as truncus arteriosus (the surviving infant was 7 weeks of age) and complex transposition of the great arteries.

\section{COMPLICATIONS}

Altogether 89 deaths occurred in hospital, of which 24 occurred on the operating table. The causes of death are listed in table IX. One other woman, who was undergoing a triple valve replacement and double vein graft, would almost certainly have died but for postoperative support by intra-aortic balloon counterpulsation. This patient left hospital and is well. There were a further 38 late deaths among the 911 patients who had left hospital at the time of writing.

The main complications are listed in table X. The largest group consisted of 35 patients who had to be returned to the operating theatre for bleeding. Only nine patients in the last 500 cases had to be reexplored for bleeding, an incidence of $1.8^{\circ} \mathrm{o}$. Two patients developed

TABLE IX-Causes of death in hospital

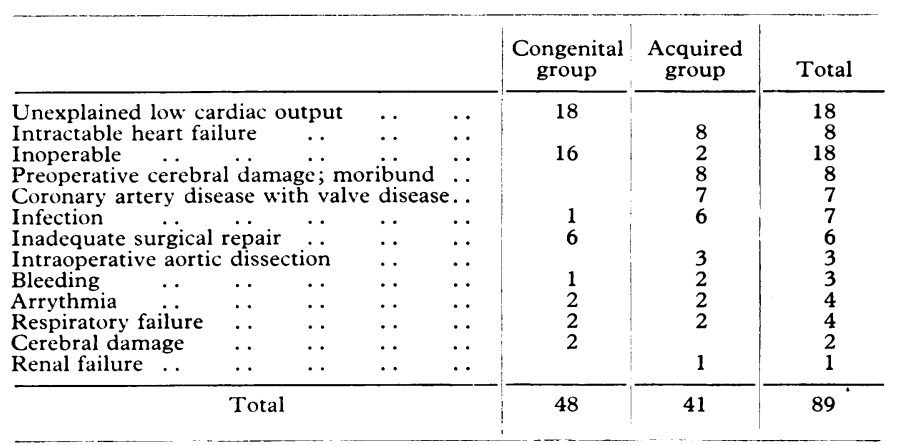

TABLE X-Complications after open heart surgery in 1000 cases

\begin{tabular}{|c|c|c|c|}
\hline & $\begin{array}{c}\text { No of } \\
\text { patients }\end{array}$ & & $\begin{array}{c}\text { No of } \\
\text { patients }\end{array}$ \\
\hline 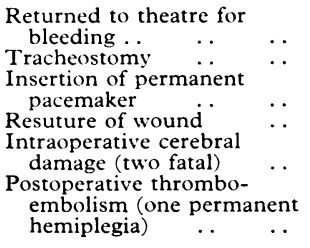 & $\begin{array}{r}35 \\
10 \\
8 \\
7 \\
5 \\
\\
2\end{array}$ & 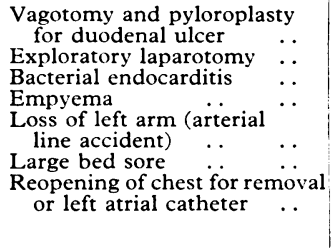 & $\begin{array}{l}2 \\
2 \\
2 \\
1 \\
1 \\
1 \\
2\end{array}$ \\
\hline
\end{tabular}


infective endocarditis on their newly acquired prosthetic valves, and both had the valves replaced, but one died.

The low incidence of perioperative cerebral complications has been gratifying. Only one patient suffered known cerebral air embolism, with full recovery. Postoperative neurological complications were seen in two patients after coronary artery procedures, presumably due to underlying cerebrovascular disease, and two children died from cerebral damage after prolonged hypoxia.

\section{RESEARCH}

An investigation (supported by a grant from the British Heart Foundation) is under way to assess the benefit of cardiac surgery to adults. Although this study is not yet complete, the results to date have shown that $80 \%$ of men of working age are fit for work within eight months of operation, whereas only $32^{\circ}{ }_{0}$, were at work before operation. A similarly gratifying increase has been shown in the ability of women to do full-time and part-time work as well as their housework and shopping unaided. A decreased dependence on others in the older age groups is also apparent.

\section{Discussion}

In a rapidly developing specialty such as cardiac surgery much interest centres on the treatment of particular conditions and it is not surprising that reports of the overall experience of individual units are seldom found. In 1968 the group at the Hammersmith Hospital reported their total experience of a decade ${ }^{4}$ reflecting the work done by a unit in a postgraduate centre with an acknowledged special interest in certain conditions and perhaps not, therefore, representing the same spectrum of surgically treatable heart disease that is found in a regional population. A more recent report from Kansas City ${ }^{5}$ gives insight into current practice in a North American community hospital, where no fewer than $67.5^{\circ}$ of the operations performed were vein bypass procedures for coronary artery disease. In our series the figure for comparable procedures was $6^{\circ}{ }_{0}$, but there is a steady increase in the number undergoing this type of surgery year by year.

Although it seems unlikely that there will be a sudden increase in demand for surgery for coronary artery disease to the extent experienced by our North American colleagues, undoubtedly good surgical results are bringing increased confidence in the vein bypass graft as a way of relieving intractable and disabling cardiac pain. We believe that we have to be prepared for a steady and substantial increase in the volume of surgery for coronary artery disease and have confirmed that this can be achieved with low operative risk. We have adopted an aggressive attitude to the surgical management of progressive or unstable angina with rewarding results for our patients and have also become increasingly thorough in identifying coronary artery disease complicating valvular heart disease. At present all patients with valve disease who have angina are submitted to coronary arteriography as part of the preoperative investigation: logistic factors prevent us from applying the ideal formula of full coronary investigation in all cases presenting for valve surgery.

\section{VALVULAR HEART DISEASE}

The largest group in our series was made up of those with valvular heart disease, and the 557 operations reported include many with additional procedures. The mortality figure of $4.3^{\circ}$ o for aortic valve replacement includes all those with additional procedures as does the figure of $5 \cdot 4^{\circ}$ o for mitral valve replacement, so that the less favourable cases are included in these statistics. These results compare favourably with the total experience in Australia for $1973(8.1 \%$ and $6.1 \%$ respectively for aortic and mitral valve replacement $)^{6}$ and it is interesting and reassuring that in our series multiple valve replacement carried a similar risk $(5 \%)$ to that for replacement of a single valve. Again, this compares favourably with other reported mortality figures for multiple valve replacement, which vary from 10.9 to $19^{\circ}{ }_{0} 0^{5} 6$

The results indicate that it is now reasonable to recommend valve replacement in any adult with symptoms and proved severe aortic stenosis and in patients with severe aortic regurgitation before irreversible myocardial deterioration has occurred. In patients with mitral valve disease operation should be recommended before the heart has become too large and the patient too incapacitated. Throughout the period reported here we have studied the coronary arteries of patients with valve disease with increasing frequency, because of the association of coronary artery disease and valve disease. We believe that this more vigorous approach to the detection of coronary artery disease and the earlier referral of patients for full assessment can lower the operative mortality still further.

Our experience suggests that in Wessex valvular heart disease is showing no sign of declining. In particular, we have shown repeatedly the value of surgery in the management of infective endocarditis at all stages of the disease. The usual practice once a patient has developed bacterial endocarditis is to administer a six-week course of antibiotic treatment, having first obtained a positive blood culture if possible. Then, if valve replacement is merited, this can be undertaken electively. If intractable heart failure supervenes before the antibiotic course has been completed, urgent valve replacement must be undertaken and the mortality of valve replacement, even in the presence of an actively infected valve, is dramatically less than if the natural course of the disease is allowed to continue. ${ }^{\top}$ There is fortunately a low incidence of subsequent infection of the valve substitute, but antibiotic cover must be given to all patients with prosthetic valves undergoing any procedure apt to cause a bacteraemia, such as dental extraction, filling, or scaling, or who are exposed to any other septic hazard-for example, abdominal, gynaecological, and genitourinary surgery.

We have also treated with benefit a growing number of older patients often suffering from degenerative as opposed to rheumatic valve disease. Although the operative mortality is, as might be expected, slightly higher in this group, operation may be very worthwhile even over the age of 70 years, and age alone is not accepted as a contraindication to surgery for treatable valvular heart disease.

The number of patients requiring reoperation after closed or open valve procedures is also increasing. No patient who has once been considered suitable for valve surgery should ever be denied further surgery if he is suffering from malfunction of either his own valves or the implanted valve substitutes, provided that adeauate left ventricular function persists.

\section{CONGENITAL HEART DISEASE}

Nearly a third of the operations performed were for congenital heart disease. This group had a higher hospital mortality. The deaths occurred mainly in the youngest infants, many of whom $N$ were desperately ill, and were partly due to our policy of definitive $N$ correction whenever possible. The results of this policy are most obvious in the group of patients with Fallot's tetralogy, in 0 whom the operative mortality $\left(24^{\circ}{ }_{0}\right)$ was disappointingly high. During the early part of this series four palliative procedures were $\stackrel{\mathscr{C}}{\rightarrow}$ done in infants with this condition. Since then all have been 0 totally corrected and the patients who died were all in the younger age group and mainly in the early part of the series. We have corrected 34 patients with Fallot's tetralogy since June $\stackrel{\mathbb{Q}}{\varrho}$ 1974,12 of whom were less than 2 years of age, with only one death, and this seems to vindicate our approach.

Similarly, patients with ventricular septal defect presenting in infancy with refractory heart failure have undergone closure of the defect rather than pulmonary artery banding. The youngest patient on whom this was successfully performed was 18 days old.

By contrast, in those infants with complex congenital defects such as single ventricle and tricuspid atresia we have been 
disappointed with a radical approach and now palliate initially and aim to correct at about the age of 5 years. If early correction is contemplated in certain conditions in which palliation is not so helpful, not only must the anatomical diagnosis be exact, but the patients must be in as good a clinical state as possible preoperatively. In this respect, early referral of these sick infants and careful maintenance of the acid base state are vital.

\section{CONCLUSION}

We have attempted to record the performance of a regional unit dealing with a full range of cardiac disease. Full back-up is necessary from biochemical, haematological, and radiological services, from the physiotherapy department, and from the blood bank, but the organisation of the unit is simple and does not need much technical support. The unit does not use large amounts of homologous blood.

Although this study was not designed to show long-term results, our own experience is confirming the results of others that the obvious early benefit is sustained in most patients as time goes on.

Necessarily the cost per patient is high when compared with simpler surgical procedures but it is probably fairer to compare the expense we incur with the overall cost of treating other life-threatening or disabling diseases if such comparisons have to be made. In terms of symptomatic relief, return to a useful and productive life, decreased dependence on others, and, in children, the improved prospects for the future, including normality at school, we believe that we are showing that the expense is justified and is a sound and proper use of resources.

We thank the members of the junior medical staff, nursing staff, technicians, laboratory staff, and many others who have contributed so much to the running of this unit during the period covered by this report.

\section{References}

${ }^{1}$ Barratt-Boyes, B G, Simpson, M, and Neutze, J M, Circulation, 1971, 43, 25.

${ }^{2}$ Ross, J K, and Monro, J L, Proceedings of the Royal Society of Medicine, $1975,68,175$.

3 Sbokos, C G, Monro, J L, and Ross, J K, Thorax, 1976, 31, 55.

4 Cleland, W P, et al, Lancet, 1968, 1, 191.

${ }^{5}$ Crouch, J A, et al, fournal of Thoracic and Cardiovascular Surgery, 1974, $68,606$.

${ }^{6}$ National Heart Foundation of Australia, Medical fournal of Australia, $1975,1,609$.

${ }^{7}$ English, T A H, and Ross, J K, British Medical fournal, 1972, 4, 598.

\title{
Today's Treatment
}

\section{Diseases of the alimentary system}

\author{
Nausea and vomiting
}

\section{DENIS GIBBS}

\section{British Medical fournal, 1976, 2, 1489-1492}

Complex processes underly the symptoms of nausea and vomiting. Presumably these mechanisms evolved to the organism's advantage. Boyle observed three centuries ago that "tis profitable for man that his stomach should nauseate and reject things that have a loathsome taste or smell." Nevertheless, though the stomach may sometimes empty itself of certain noxious substances when this is required, nausea and vomiting often seem to serve no discernibly useful function. Seasickness, the commonest form of motion sickness, may be considered as an example. Its importance is emphasised by the fact that the word nausea is derived from the Greek for a ship. Analysis of the sufferer's symptoms and signs conveys a picture of complex autonomic changes. Pallor, coldness, sweating, salivation, nausea, and anorexia precede vomiting. In addition, there may be drowsiness, headache, and lassitude. It is impossible to conceive any advantage for the sufferer once he has embarked from the security of terra firma; and the imagination is stretched to impute a teleologically protective role to seasickness as a means of curbing exploratory and adventurous instincts.

Departments of Medicine and Gastroenterology, The London Hospital, London E1

DENIS GIBBS, DM, FRCP, consultant physician
To treat the symptoms of nausea and vomiting rationally, a comprehensive diagnosis should have been established; the susceptibility and circumstances of the individual assessed; and possible hazards and disadvantages of symptomatic approaches considered. There are many conditions in which symptomatic treatment is not appropriate-for instance, nausea and vomiting are common accompaniments of abdominal disorders needing surgical treatment; or vomiting, sometimes without nausea, may be a feature of raised intracranial pressure. Similarly, when the symptoms are derived from metabolic or drug-induced disturbances, treatment of the underlying abnormality or withdrawal of a drug, rather than symptomatic measures, is needed.

Vomiting, particularly when forceful and accompanied by strain and retching, may itself have harmful consequences. The eponymous Mallory-Weiss and Boerhaave syndromes represent the most dramatic results of violent vomiting. Longitudinally placed laceration in the lower oesophagus, with resulting haemorrhage, occurs in the Mallory-Weiss syndrome, typically in someone who has had an alcoholic binge. But indulgence in alcohol is not a prerequisite for such lesions, which sometimes occur after strenuous vomiting for other reasons; patients with small sliding hiatus hernias are susceptible. Boerhaave's syndrome is an extremely rare catastrophe in which violent vomiting causes rupture of the oesophagus.

There are more prosaic but much more common consequences of vomiting. After abdominal surgery undue vomiting may interrupt recovery by delaying or preventing wound healing; or 